\title{
Kalsiyum Alüminat Çimentosunun Farklı Kür Koşullarında Atık Cam Tozu Esaslı Geopolimer Harçların Fiziksel ve Mekanik Özelliklerine Etkisi
}

\author{
İsmail İsa Atabey ${ }^{1 *}$, Cemre $\mathrm{Ay}^{2}$ \\ 1* Nevşehir Hacı Bektaş Veli Üniversitesi, İnşaat Mühendisliği Bölümü, 50300, Nevşehir, Türkiye, (ORCID: 0000-0002-7026-5579), ismailatabey@ nevsehir.edu.tr \\ ${ }^{2}$ Nevşehir Hacı Bektaş Veli Üniversitesi, Fen Bilimleri Enstitüsü, 50300, Nevşehir, Türkiye (ORCID: 0000-0001-7292-098X)), cemreay568@ gmail.com
}

(2nd International Conference on Access to Recent Advances in Engineering and Digitalization (ARACONF)-10-12 March 2021)

(DOI: $10.31590 /$ ejosat.899513)

ATIF/REFERENCE: Atabey, İ.İ., Ay, C. (2021). Kalsiyum Alüminat Çimentosunun Farklı Kür Koşullarında Atık Cam Tozu Esaslı Geopolimer Harçların Fiziksel ve Mekanik Özelliklerine Etkisi. Avrupa Bilim ve Teknoloji Dergisi, (24), 184-189.

$\ddot{\mathbf{O} z}$

Bu çalı̧̧mada atık cam tozu ile üretilen geopolimer harçların fiziksel ve mekanik özelliklerine kalsiyum alüminat çimentosunun farklı kür koşullarında etkisi araştırılmıştır. Bu amaçla atık cam tozu ve $\% 5, \% 10, \% 15, \% 20$ ve $\% 25$ oranında kalsiyum alüminat çimentoları (Isıdaç40 ve Refro50) içeren onbir farklı karışıma sahip geopolimer harçlar üretilmiştir. Harçlarda aktivatör olarak sodyum silikat kullanılmıştır. Üretilen geopolimer harçlar 24 saat $90^{\circ} \mathrm{C}$ etüv ve 24 saat hava +24 saat $90^{\circ} \mathrm{C}$ etüv olmak üzere 2 farklı küre tabi tutulmuştur. Harçlar üzerinde yayılma tablası, su emme-boşluk oranı, eğilme ve basınç dayanımı deneyleri gerçekleştirilmiştir. En yüksek 7 ve 28 günlük basınç dayanım değerleri hava+etüv küründe $\% 5$ Isıdaç40 tipi çimento ile üretilen harçlarda sırasıyla 24,2 MPa ve 25,5 MPa olarak elde edilmiştir.

Anahtar Kelimeler: Atık cam tozu, Geopolimer, Kalsiyum alüminat çimentosu, Dayanım.

\section{The Influence of Calcium Aluminate Cement on Physical and Mechanical Properties of Waste Glass Powder Based Geopolymer Mortars Under Different Curing Conditions}

\begin{abstract}
In this study, the physical and mechanical properties of geopolymer mortars made with waste glass powder under different curing conditions have been investigated. For this purpose, eleven different geopolymer mortars containing waste glass powder and $5 \%$, $10 \%, 15 \%, 20 \%$ and $25 \%$ calcium aluminate cement (Isıdaç40, and Refro50) were produced. Sodium silicate was used as activator in the mortars. The produced geopolymer mortars were subjected to two different curing conditions in an oven at $90^{\circ} \mathrm{C}$ for 24 hours and in the air for 24 hours + at $90^{\circ} \mathrm{C}$ for 24 hours in the oven. Flow table, water absorption and porosity, flexural strength, and compressive strength tests were performed on the mortars. The highest 7 and 28 days compressive strengths were obtained in mortars produced with 5\% Isıdaç40 type cement in the air for 24 hours, respectively $24.2 \mathrm{MPa}$ and $25.5 \mathrm{MPa}$.
\end{abstract}

Keywords: Waste glass powder, Geopolymer, Calcium aluminate cement, Strength.

\footnotetext{
*Sorumlu Yazar: ismailatabey@nevsehir.edu.tr
} 


\section{Giriş}

Yirmi birinci yüzyılda hızlı endüstriyel gelişme ve aşırı tüketim ciddi çevresel zararlara neden olmakta ve zararlı gaz salınımı artmaktadır. Son yıllarda çevrenin korunması ve sürdürülebilir gelişmenin sağlanması için enerji tasarrufu ve karbon salınımının azaltılması gerekliliği herkes tarafından kabul edilmektedir. $\mathrm{Bu}$ nedenle sınırlı kaynakların etkin kullanımı için atıkların geri dönüşümü sağlanmalıdır [1, 2]. Katı atıkların kullanımı ile depolama alanlarında azalma da meydana gelir. $\mathrm{Bu}$ durumda sadece enerji tüketimi ve karbondioksit emisyonu azaltılmaz aynı zamanda atık geri dönüşümü sayesinde çevresel avantajlar da elde edilebilir [3].

Çevresel etkileri ve kaynakların yönetimi açısından katı atıkların miktarını azaltmak için sürdürülebilir çabalar gerekmektedir. Dünya çapında her yıl büyük miktarda atık cam ortaya çıkması önemli bir sorundur. Tüm atık camların geri dönüştürülebilir olduğu ve cam fabrikalarında tekrar kullanılabileceği görülmesine rağmen, ana sorun toplanan camın kalitesi ve rengi arasındaki farktır. Farklı renk ve orijinli karışık camlar, yeni camda kontrol edilemeyen bir renk ve özelliklere neden olur ve geri dönüştürülemez, bu da düzenli depolama alanına atılması anlamına gelir [4, 5]. Ancak renk faktörünün önemli olmadığı inşaat vb. alanlarda kullanımı ile bu faktör de ortadan kaldırılabilir.

Silis bakımından zengin atık camların kullanımı küresel ölçekte büyük bir atık haline geldiği için alternatif bağlayıcı üretimi için göz ardı edilmemelidir [3]. Birleşmiş Milletler, dünya genelinde yıllık elde edilen katı atıkların 200 milyon ton olduğunu, bunun \%7'sini camın oluşturduğunu tahmin etmektedir. Türkiye için bu miktar 120000 ton olduğu bunun ancak 80000 tonu geri dönüştürülebildiği belirtilmektedir [6].

Atık camlar geri dönüştürülemez ise depolama alanlarında bekletilmektedir. Atık camın agrega [7], dolgu malzemesi [8], alkali ile aktifleştirilmiş bağlayıcı üretimi [5] ve katkı malzemesi olarak [9] potansiyel kullanım alanları bulunmaktadır.

Alkali ile aktifleştirilmiş bağlayıcı üretim yöntemlerinden olan geopolimerler, alüminosilikat malzemenin alkali hidroksit ve/veya alkali silikatlar ile sentezlenerek üç boyutlu amorf yapılı inorganik polimerlerdir [10]. Geopolimerizasyon sürecinde mekanik özelliklerin belirlenmesinde alüminosilikatların kimyasal kompozisyonları önemli rol oynar. İstenilen dayanım gelişiminin elde edilebilmesi için başlangıç malzemelerinde optimum oranda Silis ( $\mathrm{Si}$ ) ve Alüminanın (Al) bulunması gerekmektedir. Atık cam tozu yüksek oranda Si içerdiği için daha düşük miktarda yer alan Al miktarını arttırmak için zengin Al içeren bir malzeme ilave edilerek bileşimin değiştirilmesi bağlayıcının özelliklerini iyileştirmektedir. Kalsiyum alüminatlı çimentolar (KAÇ) zengin alümina içeriği sayesinde cam tozu ile karıştırılarak Al eksikliği telafi edilebilmektedir. [5, 11].

KAÇ'ler, uygulamaya ve alüminyum kaynağının saflığına bağlı olarak geniş bir mineral bileşim aralığına sahip olan \%38$\% 80$ arasında değişen alümina içeriği ile bir tür özel çimentodur. Bütün KAÇ'larda monokalsiyum alüminat (CA) ana fazdır ve diğer kalsiyum alüminatlar daha az reaktif olan ikincil bileşenleri oluşturur. Kimyasal bileşimleri farklı olsa da tüm KAÇ türleri geopolimer üretimi için ek alümina kaynakları olarak kullanılabilir $[5,12]$.
Literatür incelendiğinde atık camın alüminat katkılar ile geliştirilmesiyle alkaliler ile ilgili çalışmalar sınırlı sayıdadır. Cam tozu ile yapılan çalışmalarda çoğunlukla farklı malzemelerle karışımı üzerine yer almaktadır. Zhang ve Yu, cüruf harcını sodyum silikat ve sodyum hidroksit karışımı ile aktifleştirerek cam tozunun mukavemet, kuruma büzülmesi ve sülfat direnci üzerindeki etkisini değerlendirmiştir [13].

Si ve ark. \%0-20 arası cam tozu ilaveli metakaolin tabanlı geopolimerlerin mekanik özellikleri, nano boşluk yapısı ve kuruma büzülmesi davranışını araştırmışlardır. [14].

Vafaei ve Allahverdi, cam tozu tabanlı geopolimerlere kalsiyum alüminat çimentosu ilavesi üzerine çalışmışlardır. Üç farkl $\mathrm{Na}_{2} \mathrm{O}$ oranında $(\% 8, \% 10$ ve $\% 12)$ sodyum hidroksit ve sodyum silikat karışımından oluşan aktivatör çözeltisi ile üç farklı oranda $(\% 8, \% 16$ ve $\% 24)$ kalsiyum alüminat çimentosu ile cam tozunu yer değiştirerek harç hazırlamışlardır. Optimum dayanımı $\% 10 \quad \mathrm{Na}_{2} \mathrm{O}$ aktivatör oranında $\% 24$ kalsiyum alüminatlı çimento-cam tozu yer değişiminde elde etmişlerdir [5].

Bu çalışmanın amacı, Türkiye'de üretilen iki çeşit kalsiyum alüminat çimentosunun (Isıdaç40 ve Refro50) atık cam tozu tabanlı geopolimer harçlar üzerinde farklı kür koşulları etkisini araştırmaktır. Bu sebep ile farklı kür koşulları uygulanarak atık cam tozu tabanlı geopolimer harçlara kalsiyum alüminat çimentosu ikamesinin etkisi ortaya konmak için işlenebilirlik, su emme ve boşluk oranı, eğilme dayanımı ve basınç dayanımı deney yöntemleri uygulanmıştır.

\section{Materyal ve Metot}

\subsection{Malzeme Özellikleri}

Harç karışımlarında alkali ile aktive etmek amacıyla kullanılan hammaddelerden atık cam tozu Akcihan Cam Sanayi'den ve kalsiyum alüminat çimentosu (KAÇ) Çimsa Mersin çimento fabrikasından temin edilmiştir. Cam tozu tane boyutu $50 \mu \mathrm{m}$ altındadır. Aktivatör olarak kullanılan sodyum silikatın $\left(\mathrm{Na}_{2} \mathrm{SiO}_{3}\right)$ kimyasal bileşenlerinde \%61,1 $\mathrm{H}_{2} \mathrm{O}, \% 25,9$ $\mathrm{SiO}_{2}, \% 13 \mathrm{Na}_{2} \mathrm{O}$ 'dan oluşmaktadır Harç üretiminde kullanılan atık cam tozu (CT) ve kalsiyum alüminat çimentosunun kimyasal içerikleri Tablo 1'de sunulmuştur. Harç karışımlarında şebeke suyu ve özgül ağırlığı 2,68, su emme oranı \%1,97 olan dere kumu kullanılmıştır. Dere kumunun tane dağılımı Tablo 2 'de verilmiştir.

Tablo 1. Isıdaç40, Refro50 ve Cam tozunun kimyasal özellikleri

\begin{tabular}{lccc}
\hline Özellik & Isidaç40 & Refro50 & Cam Tozu \\
\hline $\mathrm{SiO}_{2}(\%)$ & 3,60 & 6,0 & 69,4 \\
\hline $\mathrm{Al}_{2} \mathrm{O}_{3}(\%)$ & 39,8 & 51,0 & 1,09 \\
\hline $\mathrm{Fe}_{2} \mathrm{O}_{3}(\%)$ & 17,05 & 2,5 & 0,48 \\
\hline $\mathrm{CaO}(\%)$ & 36,20 & 38,8 & 8,27 \\
\hline $\mathrm{MgO}(\%)$ & 0,65 & 1,0 & 4,25 \\
\hline $\mathrm{SO}_{3}(\%)$ & 0,04 & 0,2 & - \\
\hline $\mathrm{Na}_{2} \mathrm{O}(\%)$ & 0,16 & 0,3 & 12,31 \\
\hline $\mathrm{K}_{2} \mathrm{O}(\%)$ & & - & - \\
\hline $\mathrm{Cl}(\%)$ & 0,009 & - & - \\
\hline $\mathrm{K} . \mathrm{K} .(\%)$ & 0,30 & 3,03 & 2,58 \\
\hline $\mathrm{Yoğ} .\left(\mathrm{g} / \mathrm{cm}^{3}\right)$ & 3,25 & & \\
\hline
\end{tabular}


Tablo 2. Dere kumuna ait tane dağılımı

\begin{tabular}{cc}
\hline Elek Çap1, $\mathrm{mm}$ & Geçen, $\%$ \\
\hline 4,00 & 99,1 \\
\hline 2,00 & 65,1 \\
\hline 1,00 & 40,2 \\
\hline 0,5 & 21,3 \\
\hline 0,25 & 9,9 \\
\hline 0,125 & 3,7 \\
\hline 0,063 & 0,9 \\
\hline
\end{tabular}

\subsection{Deney Tasarımı}

Deneysel çalışmada, kalsiyum alüminatlı çimento (Isıdaç40 ve Refro50) içeriğgine göre her kür grubu için 5 seri ve bir grup $\% 100$ atık cam tozundan oluşan kontrol harcı olmak üzere toplam 11 farklı karışım hazırlanmıştır. Üretilen harçların karışım oranları 3 gözlü 40×40×160 mm harç kalıpları için Tablo 3'de sunulmuştur. Tüm harç karışımlarında su/bağlayıcı oranı 0.5 , kum/bağlayıcı oranı ise 3 olarak belirlenmiştir. Karışımlarda Sıvı $\mathrm{Na}_{2} \mathrm{SiO}_{3} \quad \% 10 \quad \mathrm{Na}_{2} \mathrm{O}$ oranında kullanılmıştır. Bununla birlikte, karışımlar içerdikleri kalsiyum alüminatlı çimento miktarına bağlı olarak 5 farklı seride $\% 5, \% 10, \% 15, \% 20$ ve $\% 25$ oranlarında cam tozu ile ağırlıkça yer değiştirilerek üretilmiştir.

Çözelti hazırlamak için cam kavanozlara önce sodyum silikat ardından üzerine su ilave edilmiştir. Çözeltiler ile TS EN 196-1'e [15] uygun olarak 40×40×160 mm üç gözlü kalıplarda numuneler üretilmiştir. Çözelti, cam tozu ve kalsiyum alüminatlı çimento önce karıştırma kabında 30 saniye karıştırıldıktan sonra 30 saniye içinde kum ilave edilerek karışıma devam edilmiştir. Ardından yüksek hızda 30 saniye daha mikser karıştırmaya devam etmiştir. $\mathrm{Bu}$ aşama sonunda mikser durdurulup ilk 30 saniyede kabın kenarlarındaki harç toplanarak dinlenmesi için toplam 90 saniye beklenmiştir. Daha sonra 60 saniye daha yüksek hızda karıştırmaya devam edilerek işlem tamamlanmıştır.

Taze harçlara TS EN 1015-3 [16] standardına göre yayılma tablası deneyi uygulanmıştır. Ardından karışımlar 40×40×160 mm boyutlarında 3 göze sahip harç kalıplarına iki aşamada yerleştirilmiştir. Harç kalıplarına dökülen karışımlar farklı kür koşulları için 2 gruba ayrılmıştır. 1. Grup numuneler üretildikten hemen sonra kalıplariyla birlikte 24 saat $90^{\circ} \mathrm{C}$ sıcaklıktaki etüvde kür edilmiştir. 2. Grup numuneler ise laboratuvar koşullarında yaklaşık $23 \pm 2{ }^{\circ} \mathrm{C}$ sıcaklıkta 24 saat üstü nemli bez ile kapalı tutulmuş ardından 24 saat $90^{\circ} \mathrm{C}$ sıcaklıktaki etüvde kür edilmiştir.

Sertleşmiş 28 günlük harç numunelerin su emme ve boşluk oranları belirlenmiştir. Ayrıca numuneler üzerinde TS EN 101511 [17] standardına uygun olarak eğilme ve basınç dayanımı deneyleri yapılmıştır. Her bir deneysel sonuç için 3 numuneden elde edilen ortalama sonuçlar alınmıştır. Karışım kodlamalarında CT100 tamamen atık cam tozundan oluşan kontrol grubunu, ISD kısaltması Isıdaç40 tipi KAÇ ile üretilen harçları, RFR ise Refro50 tipi KAÇ ile üretilen harç gruplarını ifade etmektedir.
Tablo 3. Harç karışım miktarları, g

\begin{tabular}{|c|c|c|c|c|c|c|}
\hline 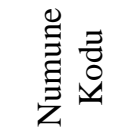 & 己ี & 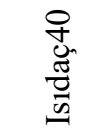 & 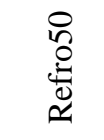 & 声 & $\bar{n}$ & 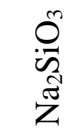 \\
\hline CT100 & 450,0 & 0 & - & 1350 & 86 & 228 \\
\hline ISD5 & 422,5 & 22,5 & - & 1350 & 86 & 228 \\
\hline ISD10 & 405,0 & 45,0 & - & 1350 & 86 & 228 \\
\hline ISD15 & 337,5 & 67,5 & - & 1350 & 86 & 228 \\
\hline ISD20 & 360,0 & 90,0 & - & 1350 & 86 & 228 \\
\hline ISD25 & 337,5 & 112,5 & - & 1350 & 86 & 228 \\
\hline RFR5 & 422,5 & - & 22,5 & 1350 & 86 & 228 \\
\hline RFR10 & 405,0 & - & 45,0 & 1350 & 86 & 228 \\
\hline RFR15 & 337,5 & - & 67,5 & 1350 & 86 & 228 \\
\hline RFR20 & 360,0 & - & 90,0 & 1350 & 86 & 228 \\
\hline RFR25 & 337,5 & - & 112,5 & 1350 & 86 & 228 \\
\hline
\end{tabular}

\section{Araştırma Sonuçları ve Tartışma}

\section{1. İşlenebilirlik}

ISD ilavesi ile \%100 CT ile üretilen harçlara göre işlenebilirlik ISD10 karışımından sonra iyileşmeye başlamıştır. RFR tipi kalsiyum alüminatlı çimento ise işlenebilirliğe daha çok etki etmiş RFR5 karışımı CT100'den $25 \mathrm{~mm}$ fazla işlenebilirlik değerine sahip iken RFR25'de $55 \mathrm{~mm}$ farka ulaşarak tüm karışımlar içindeki en yüksek işlenebilirlik değerine ulaşmıştır. Vafaei ve Allahverdi [5] cam tozu tabanlı harçlarda kalsiyum alüminat çimentosunun işlenebilirliği iyileştirdiğini belirtmiştir.

Tablo 4. Taze harç işelenebilirlik değerleri

\begin{tabular}{cc}
\hline Karışım Grubu & İşlenebilirlik, mm \\
\hline CT100 & 125 \\
\hline ISD5 & 121 \\
ISD10 & 125 \\
ISD15 & 130 \\
ISD20 & 136 \\
ISD25 & 148 \\
\hline RFR5 & 150 \\
RFR10 & 165 \\
RFR15 & 171 \\
RFR20 & 175 \\
RFR25 & 180 \\
\hline
\end{tabular}

\subsection{Su Emme ve Boșluk Oranı}

Sertleşmiş harçların su emme oranları Şekil 1'de, boşluk oranları ise Şekil 2'de verilmiştir. ISD grubu harçlarda \%5-25 KAÇ yerdeğişimi aralığında doğrudan etüv küründe \%8,1-\%9,5 aras1, hava+etüv küründe $\% 7,8-\% 9,5$ su emme oranlarına sahiptir. RFR grubu ise etüv küründe $\% 8,2-\% 9,8$, hava+etüv küründe \%8,3-\%7,8 aralığında su emme değerlerine sahiptir. Kontrol grubu CT100 karışımında ise etüvde \%8, hava+etüv küründe \% 7,9 su emme değeri elde edilmiştir. Doğrudan etüvde kür edilen numunelerin su emme oranları hava+etüv kürü uygulananlara göre daha yüksektir. Ancak kalsiyum alüminat çimentolu harçlar, kontrol karışımlarına göre su emme oranları yakın veya bir miktar daha yüksektir. Her karışımın kendi içinde etüv veya hava+etüv kürü uygulanması su emme oranlarında 
önemli bir değişikliğe de yol açmamıştır. \%5 oranında çimento ile yerdeğişimi kontrol harçlarına yakın değerler verirken genel olarak çimento değişim oranı arttıkça su emme oranı da artmıştır.

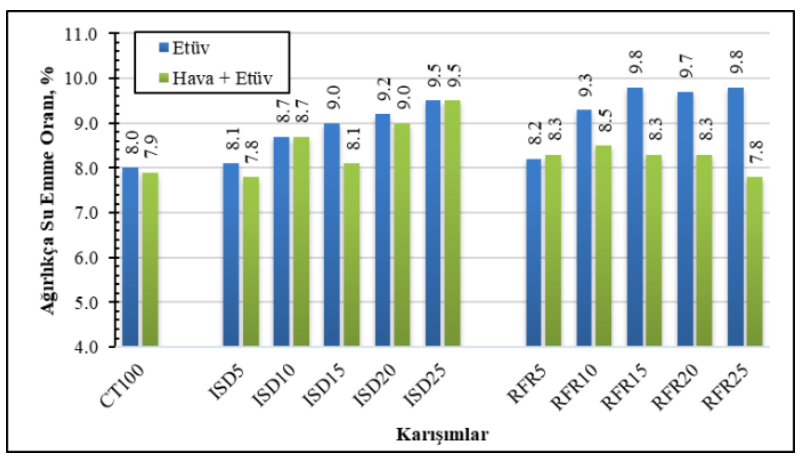

Şekil 1. Numunelerin ağırlıkça su emme oranları

Numunelerin boşluk oranları Şekil 2'de verilmiştir. Kontrol grubu CT100 harçlarının doğrudan etüv kürü sonucu boşluk oranı \%15,5 iken hava+etüv kürü sonrası \%15,3 olarak belirlenmiştir. ISD grubu harçlarda \%5-\%25 yerdeğişimi aralığında doğrudan etüv küründe $\% 16,1-\% 18,8$ arası, hava+etüv küründe \%15,7-\%18,9 boşluk oranlarına sahiptir. RFR grubu ise etüv küründe $\% 16,1-\% 19,1$, hava+etüv küründe $\% 16,3-\% 15,8$ arası boşluk oranı değerlerine sahiptir. Boşluk oranı değerlerindeki değişim su emme oranı değerlerindeki değişim ile paralellik göstermektedir.

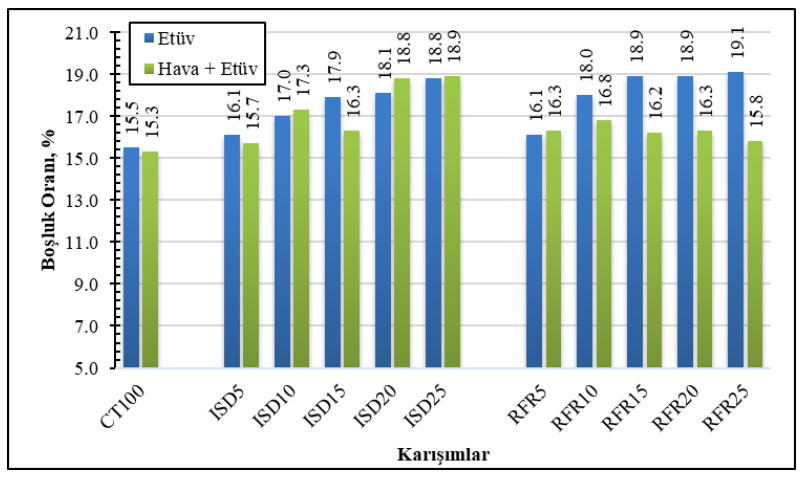

Şekil 2. Numunelerin boşluk oranları

\subsection{Eğilme Dayanımı}

Geopolimer numunelerinin 7 günlük eğilme dayanımları Şekil 3'de verilmiştir. Kontrol grubu CT100 harcının etüv kürü sonrası 5,2 $\mathrm{MPa}$, hava+etüv kürü sonrası ise 4,6 $\mathrm{MPa}$ eğilme dayanımı elde edilmiştir. Genel olarak ISD grubu harçların eğilme dayanımı kontrol grubundan düşüktür. Ancak ISD oranı $\% 5$ 'den \%25'e artış gösterdikçe eğilme dayanımındki azalış artmaktadır. En düşük eğilme dayanımı ISD25'de hava+fırın küründe 1,7 MPa iken en yüksek eğilme dayanımı ISD5'de hava+etüv küründe 5,0 MPa'dır. Kontrol grubuna en yakın eğilme dayanımı ISD5 karışımında hava+etüv kürü sonrası elde edilmiştir. RFR grubu harçlarda ise doğrudan etüv küründe $\% 5$ ve $\% 10$ oranında yer değişimi kontrol grubuna göre eşit veya bir miktar yüksektir. Fakat ISD grbubunda olduğu gibi RFR grubunda da $\% 5$ 'den $\% 25$ yerdeğişimi oranı arttıkça eğilme dayanımında düşüş artmaktadır. En yüksek eğilme dayanımı 5,8 MPa ile etüv kürü sonrası elde edilirken en düşük ise RFR25 grubunda hava+etüv kürü onrası 2,0 MPa olarak elde edilmiştir.

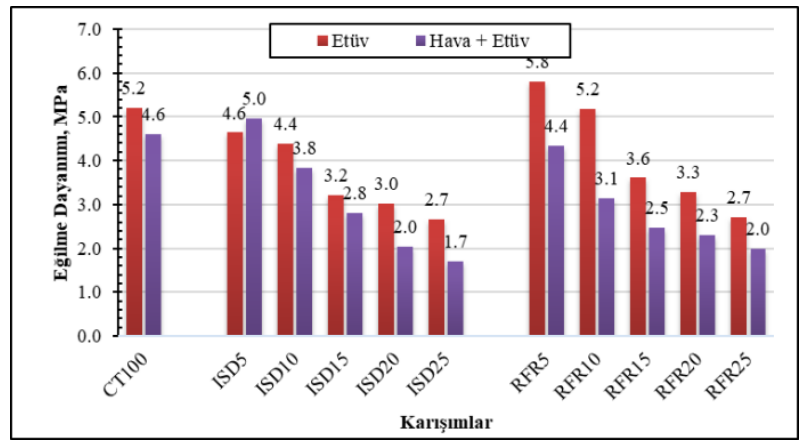

Şekil 3. 7 Günlük numunelerin eğilme dayanımları

Numunelerinin 28 günlük eğilme dayanımları Şekil 4'de verilmiştir. CT100 kontrol grubu karışımında etüvde 5,9 MPa, hava+etüv küründe 4,8 MPa eğilme dayanımı elde edilmiştir. ISD grubunda en yüksek eğilme dayanımı ISD5 karışımında etüv kürü sonrası 7,3 MPa olarak elde edilirken RFR grbunda ise RFR5 karışımında yine etüv kürü sonrası 6,8 MPa olarak elde edilmiştir. Hem ISD grubu hem RFR grubunda, etüv veya hava+etüv kürü sonrası $\% 5$ 'den $\% 25$ 'e kalsiyum alüminat çimento oranının artmasıyla eğilme dayanımında azalma görülmüştür. Ancak ISD5 ve RFR5 karışımında \%5 yer değişiminde etüv kürü sonrası eğilme dayanımında artış oluşmuş̧ır.

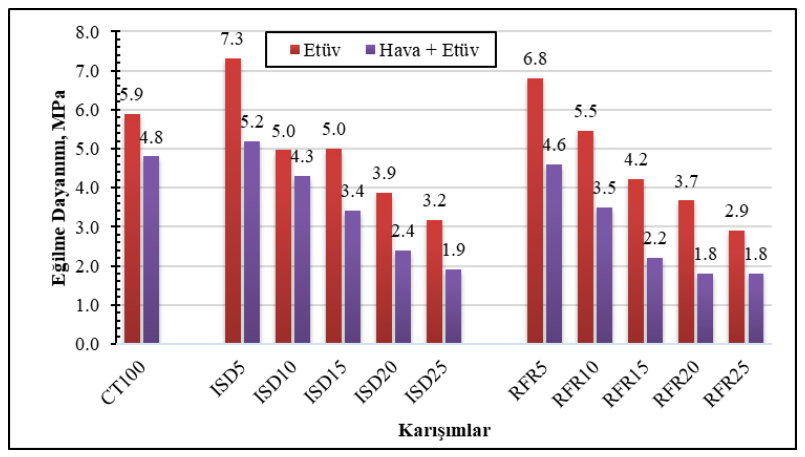

Şekil 4. 28 Günlük numunelerin eğilme dayanımları

\subsection{Basınç Dayanımı}

Geopolimer harç numunelerinin 7 günlük basınç dayanımları Şekil 5'de, 28 günlük basınç dayanımları ise Şekil 6'da verilmiştir. Harç numunelerinin tamamen cam tozu ile üretilen CT100 tipi karışımların 7 günlük doğrudan etüv sonrası 19,4 MPa, hava+etüv kürü sonrası 18,8 MPa elde dilmiştir. 28 gün sonunda ise etüv sonrası $20,0 \mathrm{MPa}$, hava+etüv sonrası ise 19,4 MPa basınç dayanımı elde edilmiştir. Cam tozu ile üretilen geoplimer harçlar kür süresine bağlı olarak önemli bir dayanım gelişimi oluşturmamıştır.

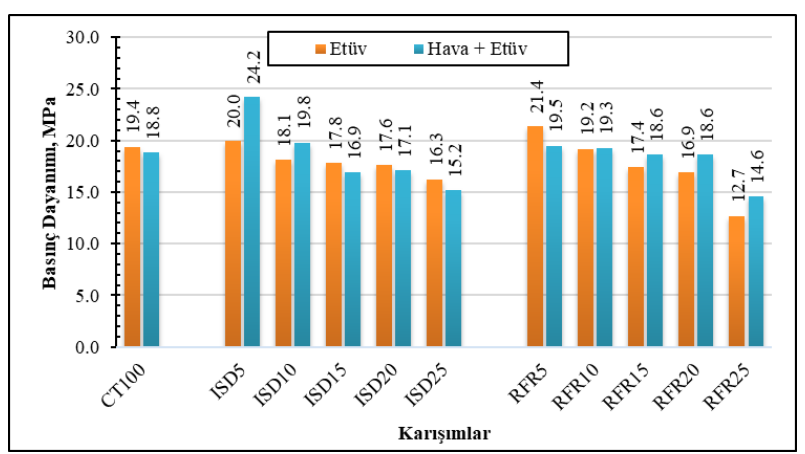


Şekil 5. 7 Günlük numunelerin basınç dayanımları

ISD grubu harçlarda 7 günlük en yüksek dayanım $24,2 \mathrm{MPa}$ ile ISD5 karışımında hava+etüv kürü sonrası oluşmuştur. Doğrudan etüv kürü sonrası ise 20,0 MPa ile CT100 kontrol karışımına yakın değerdedir. Ancak 28 günlük dayanımda ISD5 karışımı hava+etüv kürü onrası 25,5 MPa'a ulaşarak 7 günlük dayanıma göre çok büyük artış göstermemiştir. Kür süresi etkisinde \%100 cam tozu ile üretilen karışıma benzer davranış göstermiştir. RFR tipi karışımlarda ise ISD karşımlarında olduğu gibi $\% 5$ oranında yer değişimi ile artı̧ görülmekte ama ISD grubundaki artışa göre düşüktür. Refro tipi kalsiyum alüminatlı çimento grubunda en yüksek dayanım etüv küründe RFR5 karışımında 7 günlük için $21,4 \mathrm{MPa}, 28$ günlük için ise 22,1 MPa elde edilmiştir.

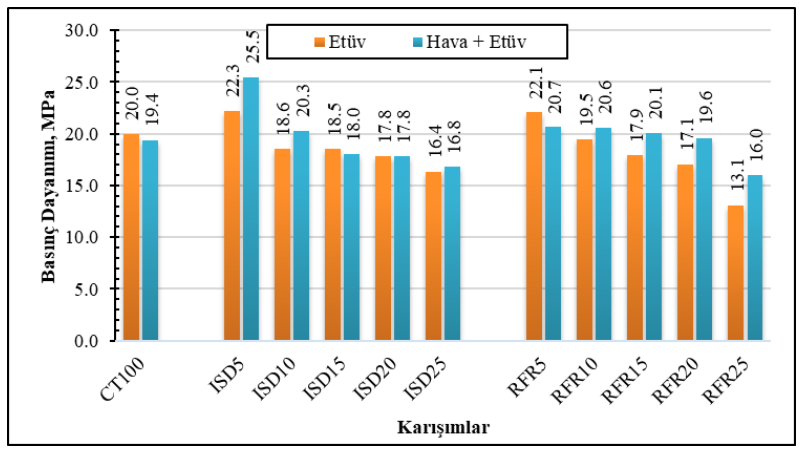

Şekil 6. 28 Günlük numunelerin basınç dayanımları

Kalsiyum alümimat çimentosunun kullanımı, kür tipi hava+firın olan ağırlıkça ISD5 ve RFR5 geopolimer harcının dayanım özelliklerini iyileştirmiştir. ISD10 ve RFR10 karışımları ise CT100 tipi kontrol karışımla yakın değerdedir. Tüm karışımların mekanik özellikleri ISD15 ve RFR15 karışımları ile düşüşe geçmektedir. Reig ve ark. [18] çalışmalarında atık seramik tozu tabanlı harçlarda KAÇ kullanımı ile \%20 yer değişimine kadar basınç dayanımın arttığını belirtmektedirler. Ayrıca Fernández-Jiménez ve ark. [19] KAÇ tipi çimentoların alüminosilikatların alkali aktivasyonunda ek bir Al kaynağı olarak kullanılabileceğini ve küçük bir miktar KAÇ varlığının malzemenin mekanik mukavemetini artıracağını ifade etmişlerdir.

Hem etüvde hem hava+etüvde kür olan numunlerde KAÇ miktarının \%5'den fazla artması ile genel olarak dayanımda artış görülmemiş CT tipi karışımlardan daha düşük basınç dayanım değerleri elde edilmiștir. Harçların hazırlandıktan hemen sonra firına konarak küre tabi tutulanlarda, çimentoların nemli ortamda reaksiyon yaptığı için hemen firında $90{ }^{\circ} \mathrm{C}$ sıcaklıkta kalması nemini kaybederek reaksiyonun yavaşlamasına sebep olacağı söylenebilir. Ayrıca 1sı ile atifleşecek CT miktarında \%5'den $\% 25$ 'e varan oranda azalma oluştuğu için \%100 CT tipi harçlara göre KAÇ ile üretilen harçların dayanımları düşük kalmıştır.

Geopolimer karışımlarında uygun miktarda reaktif $\mathrm{SiO}_{2}$ ve $\mathrm{Al}_{2} \mathrm{O}_{3}$ varlığ , artan miktarlarda reaksiyon ürünlerinin (hidrate sodyum alüminosilikat jel; N-A-S-H) oluşumuna katkıda bulunur ve bu da geopolimer bağlayıcıların yüksek mekanik performansıyla sonuçlanır. Benzer şekilde yapılan çalışmalarda aktivatörün etkin kullanımının dayanım özelliklerini geliştirdiği ortaya konmuştur [20, 21, 22, 23]. KAÇ kullanılarak ortama $\mathrm{CaO}$ ilave edilerek N-A-S-H jeli dışında C-A-S-H jeli de oluşumu sağlanmış böylece dayanımda bir miktar iyileştirme yapmıştır [11, 22]. Önceki çalışmalarda KAÇ tipi çimento kullanımında $\mathrm{NaOH}[19]$ veya $\mathrm{NaOH}-\mathrm{Na}_{2} \mathrm{SiO}_{3}$ karışımı $[5,11]$ e-ISSN : 2148-2683 ile dayanım gelişimleri incelenirken bu çalışma farklı olarak sadece $\mathrm{Na}_{2} \mathrm{SiO}_{3}$ kullanılarak \%100 CT tipi harçlara göre dayanım gelişimi belirlenmiştir.

KAÇ içeriğinin $\% 15$ 'den $\% 25$ 'e artışı harçların basınç dayanımını olumlu etkilememektedir. Ortamda fazla bulunan hidroksit iyon konsantrasyonu, alüminosilikat jellerin hızlı bir şekilde çökelmesine neden olarak daha düşük bir basınç mukavemeti ile sonuçlanmaktadır $[11,24,25]$.

\section{Sonuçlar}

- Cam tozunun işlenebilirlik değeri Isıdaç40 tipi çimento ile $23 \mathrm{~mm}$, Refro50 tipi çimento ile $55 \mathrm{~mm}$ 'ye kadar artış göstermiştir. Özellikle Refro50 tipi kalsiyum alüminatlı çimento yüksek işlenebilirlik özelliği sağlamıştır.

- Isıdaç40 tipi çimento ile üretilen harçlarda kür tipi genel olarak su emme ve boşluk oranında dikkate değer bir fark oluşturmazken, Refro50 tipi çimento ile üretilen harçlar hava+etüv küründe doğrudan etüv kürüne göre düşük su emme ve boşluk oranlarına sahiptir.

- Hem Isıdaç40 hem Refro50 tipi çimento ikamesi yapılan harçlarda 7 günlük eğilme dayanımında önemli bir gelişme görülmezken, 28 günlük numunelerde her iki çimento grubu için de etüv kürü sonrası $\% 5 \mathrm{KAÇ-}$ cam tozu yer değişimi yapılan karışımlarda yüksek eğilme dayanımı elde edilmiştir.

- Etüv veya hava+etüv kürü cam tozu tabanlı geopolimer harçların basınç dayanımında 7 günden 28 güne kür süresinin artışıyla önemli bir fark oluşturmamıştır.

- Isıdaç40 tipi çimento ile üretilen 28 günlük harçların basınç dayanımı $\% 5$ oranında cam tozu ile yer değişiminde hava+etüv kürü sonrası $25,5 \mathrm{MPa}$ elde edilmiştir. Hava +etüv kürü ile 19,4 $\mathrm{MPa}$ basınç dayanıma sahip CT100 tipi harçlara göre \%31 oranında daha yüksek dayanıma ulaşııııştır.

\section{Teşekkür}

$\mathrm{Bu}$ çalışmanın yürütülmesine ABAP20F20 nolu proje ile destek veren Nevşehir Hacı Bektaş Veli Üniversitesi Bilimsel Araştırma Projeleri Koordinasyon Birimine teşekkür ederiz.

\section{Kaynakça}

[1] W. C. Wang, B. T. Chen, H. Y. Wang, and H. C. Chou, (2016). "A study of the engineering properties of alkaliactivated waste glass material (AAWGM)," Constr. Build. Mater., vol. 112, pp. 962-969.

[2] C. C. Wang, H. Y. Wang, B. T. Chen, and Y. C. Peng, (2017). "Study on the engineering properties and prediction models of an alkali-activated mortar material containing recycled waste glass," Constr. Build. Mater., vol. 132, pp. 130-141.

[3] H. Du and K. H. Tan, (2017). "Properties of high volume glass powder concrete," Cem. Concr. Compos., vol. 75, pp. 22-29. 
[4] Y. Jani and W. Hogland, (2014). "Waste glass in the production of cement and concrete - A review," J. Environ. Chem. Eng., vol. 2, no. 3, pp. 1767-1775.

[5] M. Vafaei and A. Allahverdi, (2017). "High strength geopolymer binder based on waste-glass powder," Adv. Powder Technol., vol. 28, no. 1, pp. 215-222.

[6] I. B. Topçu and M. Canbaz, (2004). "Properties of concrete containing waste glass," Cem. Concr. Res., vol. 34, no. 2, pp. 267-274.

[7] T. M. Borhan, (2012). "Properties of glass concrete reinforced with short basalt fibre," Mater. Des., vol. 42, pp. 265-271.

[8] V. Vaitkevičius, E. Šerelis, and H. Hilbig, (2014). "The effect of glass powder on the microstructure of ultra high performance concrete," Constr. Build. Mater., vol. 68, pp. 102-109.

[9] M. Mirzahosseini and K. A. Riding, (2015). "Influence of different particle sizes on reactivity of finely ground glass as supplementary cementitious material (SCM)," Cem. Concr. Compos., vol. 56, pp. 95-105.

[10] J. Davidovits, (2015). Geopolymer Chemistry and Applications, 4th ed. Saint-Quentin: Institut Géopolymère.

[11] M. Vafaei and A. Allahverdi, (2016). "Influence of calcium aluminate cement on geopolymerization of natural pozzolan," Constr. Build. Mater., vol. 114, pp. 290-296.

[12] E. Najafi Kani, A. Allahverdi, and J. L. Provis, (2012). "Efflorescence control in geopolymer binders based on natural pozzolan," Cem. Concr. Compos., vol. 34, no. 1, pp. $25-33$.

[13] L. Zhang and Y. Yue, (2018). "Influence of waste glass powder usage on the properties of alkali-activated slag mortars based on response surface methodology," Constr. Build. Mater., vol. 181, pp. 527-534.

[14] R. Si, Q. Dai, S. Guo, and J. Wang, (2020). "Mechanical property, nanopore structure and drying shrinkage of metakaolin-based geopolymer with waste glass powder," J. Clean. Prod., vol. 242, p. 118502.

[15] TS EN 196 -1, (2016). Çimento Deney Metotları - Bölüm 1: Dayanım Tayini. Türk Standartları Enstitüsü, Ankara.

[16] TS EN 1015-3, (2006). Kagir harc1- Deney metotlar1Bölüm 3: Taze harç kıvamının tayini (yayılma tablası ile). Türk Standartları Enstitüsü, Ankara.

[17] TS EN 1015-11/A1, (2013). Kâgir Harc1-Deney Metotlar1Bölüm 11: Sertleşmiş Harcın Basınç ve Eğilme Dayanımının Tayini, Türk Standartları Enstitüsü, Ankara.

[18] Reig, L., Soriano, L., Tashima, M. M., Borrachero, M. V., Monzó, J., \& Payá, J. (2018). Influence of calcium additions on the compressive strength and microstructure of alkali-activated ceramic sanitary-ware. Journal of the American Ceramic Society, 101(7), 3094-3104.

[19] Fernández-Jiménez, A., Palomo, A., Vazquez, T., Vallepu, R., Terai, T., \& Ikeda, K. (2008). Alkaline activation of blends of metakaolin and calcium aluminate. Journal of the American Ceramic Society, 91(4), 1231-1236.

[20] Kaya, M., \& Köksal, F. (2020). Effect of cement additive on physical and mechanical properties of high calcium fly ash geopolymer mortars. Structural Concrete.

[21] Çelikten, S., Sarıdemir, M., \& Akçaözoğlu, K. (2020). Effect of calcined perlite content on elevated temperature behaviour of alkali activated slag mortars. Journal of Building Engineering, 32, 101717.
[22] Yurt, Ü. (2020). An experimental study on fracture energy of alkali activated slag composites incorporated different fibers. Journal of Building Engineering, 101519.

[23] Yurt, Ü. (2020). High performance cementless composites from alkali activated GGBFS. Construction and Building Materials, 264, 120222.

[24] W.K.W. Lee, J.S.J. van Deventer, (2002). The effects of inorganic salt contamination on the strength and durability of geopolymers, Coloids Surf. A 211 (2-3) 115-126.

[25] Atabey. İ.İ., Bayer Oztürk, Z. (2021). Seramik Sağlık Gereci Atıklarının Geopolimer Harç Üretiminde Kullanılabilirliğinin Araştırılması, International Journal of Engineering Research and Development, 13 (1) 212-219. 